\title{
The Safety and Efficacy of Cervical Laminectomy and Fusion versus Cervical Laminoplasty Surgery in Degenerative Cervical Myelopathy: A Prospective Randomized Trial
}

\author{
Mohamed Elmallawany, Haitham Kandel, Mohamed A. R. Soliman*, Tarek Ahmed Tareef, Ahmed Atallah, Ahmed Elsaid, \\ Wael Elmahdy
}

Department of Neurosurgery, Faculty of Medicine, Cairo University, Cairo, Egypt

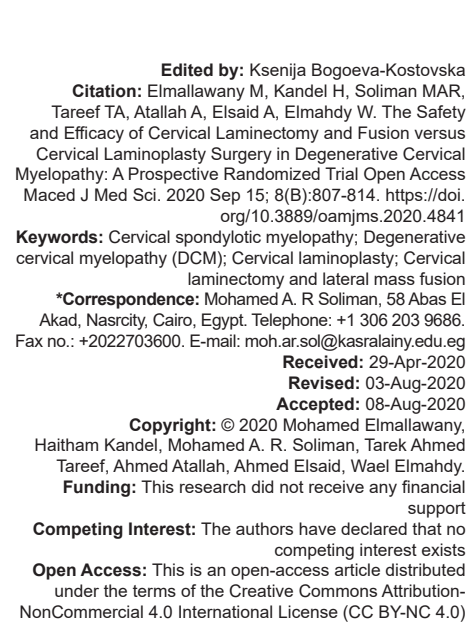

\section{Introduction}

Degenerative cervical myelopathy (DCM) is a leading cause of disability among elderly population. It results from progressive narrowing of the cervical spinal canal due to the degeneration of its components causing progressive compression of the spinal cord [1], [2]. Compression of the spinal cord could be ventral as herniated cervical disc and osteophyte or dorsal as hypertrophied facet and ligamentum flavum. This compression may be present at one level or involving multiple levels which is more common [3]. DCM has variant forms of neurological manifestations as neck pain, numbness, sensory affection, weakness, and symptoms suggestive of upper motor affection as spasticity [4]. Magnetic resonance imaging (MRI) is the gold standard test for diagnosing DCM as it provides intramedullary details of the pathology of spinal cord and is non-invasive [5]. For surgical management of DCM, surgery is indicated for a modified Japanese Orthopedic Association (mJOA) score of $\leq 12$. For patients with mJOA score of $>12$ on presentation, surgery is criticized according to an individualized basis [6]. The aim of surgery in DCM is adequate decompression with preservation of spinal stability to prevent delayed deformity and neurological deterioration so the surgical approach is determined according to the clinical presentation and radiological images [7]. Different surgical approaches are used, they either anterior including anterior cervical discectomy and corpectomy or posterior including laminectomy, laminectomy with lateral mass fixation, and laminoplasty [8]. Both cervical laminoplasty (CLP) and laminectomy with lateral mass fixation are used to treat DCM because of cervical canal stenosis by expanding the spinal bony canal for the spinal cord [9]. Our study aims to compare CLP with posterior laminectomy and fusion in the treatment of multiple levels DCM as regard the neurological outcome of each modality and radiological outcome. 


\section{Patients and Methods}

This study was conducted prospectively on 30 patients with multiple levels DCM as verified clinically and radiologically operated on in the Neurosurgery Department in Cairo University Hospitals in the period from January 2018 to September 2018.

These 30 patients were given successive numbers according to their order of presentation and then were allocated according to these numbers into one of two groups (patients with odd numbers were allocated into the first group and those with even numbers were allocated into the second group, each group consisting of 15 patients). Group A included 15 patients operated on by cervical laminectomy and lateral mass fixation. Group B included 15 patients operated on by laminoplasty. Patients included in this study had aged more than 40 years, DCM caused by multisegmental spinal stenosis ( $\geq 2$ segments), lordotic cervical curve, no history of previous cervical operations, medically fit for surgery, and compliance to the required follow-up. Patients that were excluded had age $<40$ years, DCM caused by single-segmental spinal stenosis, kyphotic cervical spine curve, medically unfit for surgery, associated ossified posterior longitudinal ligament, and cervical motion more than $3 \mathrm{~mm}$ on dynamic views.

After taking a full detailed history and clinical examination were done including motor power using Medical Research Council grading system for muscle strength and muscle tone using the modified Ashworth scale. Visual analog score (VAS) was used for grading of pre-operative neck pain and upper limb pain. Furthermore, the neck disability index (NDI) was used for pre-operative neck pain and functional state. For pre-operative assessment of myelopathy and functional state, the Nurick scale and mOJA were used. Regarding investigations, routine preoperative laboratories were done. Plain X-ray dynamic views were done for all patients also MRI cervical spine with sagittal and axial cuts. Cobb's angle was calculated preoperatively on a plain X-ray lateral view.

\section{Operative technique}

\section{Cervical laminectomy and lateral mass fixation (Group A)}

Under general anesthesia, the patient is carefully rolled into prone position followed by skin incision and subperiosteal muscle separation, the margins of the lateral mass are identified. The entry point was designed according to the Anderson technique that consists of screw placement $1 \mathrm{~mm}$ medial to the middle of the mass, $30^{\circ}$ of lateral divergence, and placement $15^{\circ}$ cephalad. Selftaping titanium screws were used with the following measurements $(3.5 \mathrm{~mm}$ diameter and 12,14 , and
$16 \mathrm{~mm}$ length). After inserting all screws, we started laminectomy. Finally, we remodeled the neck in the lordotic posture gently without rough maneuver and fix the titanium rods to the screws.

\section{Single door laminoplasty (Group B)}

Under general anesthesia, the patient is carefully rolled into prone position followed by skin incision and subperiosteal muscle separation, the lamina is exposed then using 2 or $3 \mathrm{~mm}$ cutting burr or high-speed microdrill, a trough was made at the junction of the lamina and lateral mass from $\mathrm{C} 3$ to $\mathrm{C} 7$ by decorticating the posterior aspect of the lamina. Then using Kerrison, we remove the thin rim of the remnant lamina and associated ligamentum flavum. For the hinged side of laminoplasty, $2 \mathrm{~mm}$ cutting or $6 \mathrm{~mm}$ diamond burr was used. Another trough is made at the spinolaminar line removing the outer cortex of the lamina and about half of the cancellous bone leaving the inner half of the cancellous bone with the inner cortex intact without violation of the facet joint to prevent postoperative instability. Caution is taken not to violate the inner cortex and cancellous bone as they are used to make greenstick fracture at the hinged side. The trough created at the hinged side was wide, so the walls of the trough did not contact each other early preventing further opening of the door and proper decompression. Then, spinous processes of the released laminae were pushed gently toward the hinged side to create a greenstick fracture in the hinged side of the lamina and open the spinal canal in the separated side of lamina. The spinal canal was kept open by fixing it in the maximum opened position by miniplate and screws fixed to the lamina and spinous process from one side and lateral mass on the opposite side.

\section{Post-operative outcome measures and follow-up}

\section{Radiological measures}

On the $1^{\text {st }}$ day and at 1 year, post-operative plain X-rays were done to check the hardware position and to detect if there is any change in the cervical curvature (C2 to C7 Cobb's angle).

\section{Clinical measures}

The patient's myelopathy grade (Nurick and mJOA), neck and radicular pain (VAS), and disability (NDI) were assessed on day 1 post-operative, 6 months postoperative, and 1 year post-operative and were compared to the pre-operative status. Finally, Odom's criteria were used to evaluate the post-operative patient's satisfaction.

\section{Statistical methods}

The Chi-square test, Fisher's exact test, and unpaired Student's t-test were used as appropriate to 
analyze the preoperative demographic characteristics, clinical presentations (pre-operative NDI, mJOA, Nurick's, and VAS scores), and clinical outcomes (postoperative complications and NDI, mJOA, Nurick's, and VAS scores) difference between the two groups. The variations in each group over a period of time were analyzed using the paired Student's t-test. Statistical significance was set at $p<0.05$.

\section{Results}

The series included 30 cases suffering from DCM. Patient demographics and clinical presentations are shown in Table 1.

Table 1: Patient demographics and clinical presentation

\begin{tabular}{|c|c|c|c|c|c|}
\hline \multirow[t]{2}{*}{ Variable } & \multicolumn{2}{|c|}{ Group A } & \multicolumn{2}{|c|}{ Group B } & \multirow[t]{2}{*}{$p$-value } \\
\hline & No. & $\%$ & No. & $\%$ & \\
\hline \multicolumn{6}{|l|}{ Sex distribution } \\
\hline Males & 11 & 73.3 & 10 & 66.7 & 0.69 \\
\hline Females & 4 & 26.7 & 5 & 33.3 & 0.69 \\
\hline Age distribution & No. & $\%$ & No. & $\%$ & $p$-value \\
\hline $40-49$ & 4 & 26.7 & 2 & 13.3 & 0.36 \\
\hline $50-59$ & 8 & 53.3 & 9 & 60 & 0.71 \\
\hline $60-69$ & 3 & 20 & 4 & 26.7 & 0.67 \\
\hline Symptoms & No. & $\%$ & No. & $\%$ & $p$-value \\
\hline Neck pain & 15 & 100 & 15 & 100 & 1 \\
\hline Numbness & 12 & 80 & 8 & 53.3 & 0.12 \\
\hline Heaviness in U.L or L.L & 11 & 73.3 & 13 & 86.7 & 0.36 \\
\hline Brachialgia & 11 & 73.3 & 8 & 53.5 & 0.26 \\
\hline Sphincteric disturbance & 6 & 40 & 6 & 40 & 1 \\
\hline Signs & No. & $\%$ & No. & $\%$ & $p$-value \\
\hline UL weakness & 14 & 93.3 & 15 & 100 & 0.31 \\
\hline UL and LL weakness & 9 & 60 & 11 & 73.3 & 0.44 \\
\hline Sensory disturbance & 6 & 40 & 5 & 33.3 & 0.7 \\
\hline Spasticity & 8 & 53.3 & 11 & 73.3 & 0.26 \\
\hline Hyperreflexia & 12 & 80 & 14 & 93.3 & 0.28 \\
\hline Positive Babinski sign & 13 & 86.7 & 11 & 73.3 & 0.36 \\
\hline Positive Hoffmann reflex & 5 & 33.3 & 3 & 20 & 0.41 \\
\hline Ankle clonus & 9 & 60 & 7 & 46.7 & 0.46 \\
\hline
\end{tabular}

\section{Intraoperative outcomes}

The mean operative duration was significantly longer in Group A (192.6 $\pm 31.2 \mathrm{~min})$ compared to only $142 \pm 27.06 \mathrm{~min}$ ( $p<0.001)$. Furthermore, the mean estimated blood loss (EBL) for Group A was significantly larger (311.3 $\pm 104.9 \mathrm{CC})$ compared to Group B $(193.3 \pm 79.47 C C)(p<0.05)$. Regarding the intraoperative complications, dural tear occurred in two cases in Group A and one case in Group B and all the cases were repaired with a watertight dural repair. Furthermore, in Group A, we reported lateral mass fracture during insertion of the screw and this level was bypassed in fixation.

\section{Post-operative Outcomes}

\section{Clinical outcomes}

Pain (VAS)

Pre-operative mean neck pain scores on the VAS were $6.53 \pm 1.15$ in Group $A$ and $6.07 \pm 1.18$ in Group B ( $p=0.29)$, and pre-operative mean upper limb pain scores were $5.47 \pm 1.63$ and $5.8 \pm 1.47$ $(p=0.57)$, respectively. These pre-operative scores were not significantly different between the groups. The remaining overall mean neck pain scores on the VAS were $4.13 \pm 1.02$ in Group A at 1 year, compared with $5 \pm 1.03$ in Group B. Regarding neck pain, compared to the pre-operative pain, both groups had significant improvement on the VAS ( $p<0.001)$, and the improvements were significantly better in Group $A$ $(p<0.05)$. The remaining overall average upper limb pain scores on the VAS were $3.07 \pm 1.48$ in Group A at 1 year, compared with $3 \pm 1.31$ in Group $B(p=0.89)$. Furthermore, the upper limb pain compared to the preoperative pain, both groups had significant improvement on the VAS ( $p<0.001)$, and there was no significant difference between the two groups ( $p>0.05)$ (Table 2).

Table 2: Post-operative outcomes

\begin{tabular}{|c|c|c|c|}
\hline Outcome & Group A & Group B & Significance (p-value) \\
\hline \multicolumn{4}{|l|}{ Neck pain VAS } \\
\hline Pre-operative & $6.53 \pm 1.15$ & $6.07 \pm 1.18$ & 0.29 \\
\hline 1 year post-operative & $4.13 \pm 1.02$ & $5 \pm 1.03$ & $p<0.05^{\star}$ \\
\hline \multicolumn{4}{|l|}{ Upper limb pain VAS } \\
\hline Pre-operative & $5.47 \pm 1.63$ & $5.8 \pm 1.47$ & 0.57 \\
\hline 1 year post-operative & $3.07 \pm 1.48$ & $3 \pm 1.31$ & 0.89 \\
\hline \multicolumn{4}{|l|}{ Neck disability index } \\
\hline Pre-operative & $28.53 \pm 5.04$ & $27.07 \pm 5.26$ & 0.44 \\
\hline 1 year post-operative & $14.8 \pm 4.32$ & $17.2 \pm 4.94$ & 0.2 \\
\hline \multicolumn{4}{|l|}{ Nurick's grade } \\
\hline Pre-operative & $2.8 \pm 0.75$ & $3.07 \pm 0.68$ & 0.31 \\
\hline $\begin{array}{l}1 \text { year post-operative } \\
\text { mJOA }\end{array}$ & $1.4 \pm 0.61$ & $1.67 \pm 0.6$ & 0.23 \\
\hline Pre-operative & $11.73 \pm 0.92$ & $11.3 \pm 1.24$ & 0.33 \\
\hline 1 year post-operative & $14.6 \pm 1.58$ & $13.8 \pm 1.25$ & 0.14 \\
\hline \multicolumn{4}{|l|}{ Odom's criteria } \\
\hline Excellent & $13.3 \%$ & $20 \%$ & 0.62 \\
\hline Good & $66.7 \%$ & $53.3 \%$ & 0.46 \\
\hline Fair & $13.3 \%$ & $20 \%$ & 0.62 \\
\hline Poor & $6.7 \%$ & $6.7 \%$ & 1 \\
\hline \multicolumn{4}{|l|}{ C2-7 Cobb's angle } \\
\hline Pre-operative & $8.73^{\circ} \pm 6.08^{\circ}$ & $9.42^{\circ} \pm 6.1^{\circ}$ & 0.76 \\
\hline 1 year post-operative & $9.73^{\circ} \pm 6.22^{\circ}$ & $9.2^{\circ} \pm 4.43^{\circ}$ & 0.79 \\
\hline
\end{tabular}

NDI

The pre-operative average NDI scores were $28.53 \pm 5.04$ in Group A and $27.07 \pm 5.26$ in Group B. The remaining overall average disaKbility scores on the NDI were $14.8 \pm 4.32$ in Group A at 1 year, compared with $16.27 \pm 5.13$ in Group B. Both groups showed significant improvement at 1 year post-operative $(p<0.001)$. There was no significant difference in postoperative improvement $(p=0.2)$ between the groups.

\section{Nurick's myelopathy grading}

In our study, results showed that the mean pre-operative Nurick's scores were $2.8 \pm 0.75$ in Group A and $3.07 \pm 0.68$ in Group B ( $p=0.31)$ with an overall improvement in the mean post-operative Nurick's scores of Group A $1.4 \pm 0.61$ and $1.67 \pm 0.6$ in Group B ( $p=0.23)$. Both groups showed significant improvement at 1 year post-operative compared to the pre-operative values $(p<0.001)$ and there was no significant difference in post-operative improvement $(p=0.9)$ between the groups. 
mJOA score

In our study, results showed that the mean pre-operative mJOA score was $11.73 \pm 0.92$ in Group A and $11.3 \pm 1.24$ in Group B ( $p=0.33)$ with an overall improvement in the mean post-operative mJOA scores of $14.6 \pm 1.58$ in Group A and $13.8 \pm 1.25$ in Group B with $p>0.05$ which is statistically insignificant. The postoperative mJOA compared to the pre-operative mJOA, both groups had significant improvement on mJOA ( $p<0.001)$, and there was no significant difference between the two groups $(p>0.05)$.

\section{Odom's criteria}

In our study, results showed no significant difference between the two groups after using Odom's criteria to evaluate the patient's satisfaction with the outcome of the procedure. In Group A, the outcome score using Odom's criteria was good or excellent in $80 \%$, while in Group B, the score was good or excellent in $73.3 \%$ with $p>0.05$ which is statistically insignificant.

\section{Sphincteric manifestations}

Only 10 patients out of 12 patients suffering from sphincteric manifestations showed improvement (one in each group).

\section{Post-operative complications}

In our study, the rate of complications was nearly the same between both groups. In Group A, complications included one case of transient C5 palsy $(6.7 \%)$, two cases of superficial infection (13.3\%) while in Group B, complications included a case of instrumentation failure $(6.7 \%)$ and breakage of the hinged side of laminoplasty with neural compression, the patient presented with severe radiculopathy and mild weakness for which the patient required revision surgery and removal of the plate and lateral mass screws were inserted, and one case of superficial infection (6.7\%).

None of the two groups developed any of the following complications: Deep infection, worsening of myelopathy on final assessment (all weaknesses reported in both groups were transient and improved on reassessment), vascular injury, or hematoma, and there were no mortality cases during the study period.

\section{Radiographic outcomes}

The mean pre-operative C2-7 Cobb's angle was $8.73^{\circ} \pm 6.08^{\circ}$ in Group $A$ and $9.42^{\circ} \pm 6.1^{\circ}$ in Group $B(p=0.76)$ with an overall improvement in the mean post-operative C2-7 Cobb's angle at 1 year follow-up of $9.73^{\circ} \pm 6.22^{\circ}$ in Group A and $9.2^{\circ} \pm 4.43^{\circ}$ in Group $B(p=0.79)$. There was an insignificant change in the post-operative C2-7 Cobb's angle compared to the pre-operative C2-7 Cobb's angle in both groups ( $p>$ 0.05). However, the improvements in the Cobb's angle were significantly better in Group A ( $p<0.05)$.

\section{Hospital stay}

Finally, the average hospital stay for Group A was $4.3 \pm 1.1$ days while the average hospital stay for Group B was $3.1 \pm 1.1$ days with $p<0.05$ which is statistically significant.

\section{Discussion}

This study aimed to compare laminectomy with lateral mass fixation versus CLP in the treatment of multiple levels DCM as regard the neurological outcome of each modality in the form of improvement of the symptoms or appearance of complications and radiologically regarding change of cervical curvature.

\section{Demographics}

In our study, age ranged from 44 to 65 years with a mean age of $54.5 \pm 5.5$ years. In Group A, 4 patients $(26.7 \%)$ had $<50$ years and 2 patients $(13.3 \%)$ in Group B. Furthermore, the number of patients exceeding 50 years was 11 (73.3\%) in Group A and $13(86.7 \%)$ in Group B. Highsmith et al. conducted a retrospective study on 56 patients who were surgically treated for DCM. Their age ranged from 42 to 81 years. In laminectomy and fusion group (26 patients), age ranged from 44 to 81 years (mean 58 years) and the age in the laminoplasty group (30 patients) ranged from 44 to 81 years (mean 61 years) [10]. Manzano et al. conducted a prospective randomized study on 16 patients suffering from DCM. The mean age was 59 years; the age range was from 41 to 75 years. Nine patients were randomized to laminoplasty. Their mean age was 61 years. Seven patients were randomized to the laminectomy and fusion group their mean age was 55 years [11].

\section{Symptoms}

In our study, neck pain was the most common presenting symptom in both groups (100\%). The numbness was the second common symptom in Group A 12 patients $(80 \%)$. The sphincteric disturbance is equal in both groups 6 patients (40\%). Lau et al. conducted a cohort retrospective study including 145 patients: 101 who underwent laminoplasty and 44 who underwent laminectomy and fusion. Ninety-six patients $(66.2 \%)$ of a total of 145 patients included in this study experienced preoperative neck pain. 
Sixty-three patients of 101 patients $(62.5 \%)$ included in the laminoplasty group experienced pre-operative neck pain. Thirty-three patients $(75 \%)$ of 44 patients included in the laminectomy and fusion group experienced preoperative neck pain [12].

\section{Signs}

In our study, motor deficit involving the upper limbs was the most common sign in both groups detected in $96.7 \%$ of examined patients, 14 patients $(93.3 \%)$ in Group A and 15 patients (100\%) in Group B. Motor deficits involving both upper and lower limbs were detected in $66.7 \%$ of cases, 9 patients $(60 \%)$ in Group A and 11 patients (73.3\%) in Group B. Twelve patients of Group A experienced hyperreflexia (80\%) and 14 patients of Group B experienced hyperreflexia (93.3\%). Positive Babinski sign in 13 patients in Group A $(86.7 \%)$ and 11 patients in Group B (73.3\%). Twelve patients were complaining of pre-operative numbness in Group A ( $80 \%)$ and 8 patients were complaining of pre-operative numbness in Group B (53.3\%).

Du et al. in their retrospective study the most common reported sign was hyperreflexia, 21 patients of 32 patients included in laminectomy and fusion group had hyperreflexia (65.6\%), 25 patients of 36 patients included in the laminoplasty group had hyperreflexia $(69.4 \%)$. The second most common sign was upper limb weakness 19 patients of 32 patients in laminectomy and fusion group suffering from weakness in upper extremities (59.3\%). Twentytwo patients of 36 patients in laminoplasty group were suffering from upper extremities weakness (61.1\%). They also reported that 16 patients of 32 patients in laminectomy and fusion group were complaining of numbness $(50 \%), 19$ patients of 36 patients included in the laminoplasty group had numbness (52.7\%), 7 patients of 32 patients in laminectomy and fusion group had Babinski sign (21.8\%), and 9 patients of 36 patients in the laminoplasty group had Babinski sign (25\%) [13].

\section{Operative duration}

In our study, the mean operative time was $192.6 \pm 29.03$ for the laminectomy and fusion group and was $142 \pm 27.06$ for the laminoplasty group which is statistically significant. Yang et al. documented in a retrospective study conducted on 141 patients, 66 patients underwent laminectomy and fusion and 75 patients underwent laminoplasty with mean operative time $173.79 \pm 29.18$ min for the laminectomy and fusion group and $145.07 \pm 27.13$ in the laminoplasty group [14]. This confirms our results that laminoplasty is a time-saving procedure than the laminectomy and fusion and may be useful in elderly patients with associated comorbidities that prevent long duration of anesthesia. Furthermore, long operative duration may increase the rate of infection.

\section{Blood loss}

In our study, the mean EBL for Group A was significantly larger ( $311.3 \pm 104.9 \mathrm{CC})$ compared to Group B (193.3 \pm 79.47 CC) (p-value <0.05). Lau et al. in their retrospective study reported mean $\mathrm{EBL}$ in the laminectomy and fusiongroup 325.0 CC and 196.6CC in the laminoplasty group [12]. Yang et al. reported in their retrospective study mean EBL $310.91 \pm 50.92$ in the laminectomy and fusion group and $284.53 \pm 27.13$ in the laminoplasty group [14]. This increase in blood loss in laminectomy and fusion group may be explained by bleeding from veins around the spinal cord after laminectomy and by additional muscle exposure (dissection to the lateral masses), spinal fixation, and bone arthrodesis, which can result in greater intraoperative blood loss.

\section{Pain scores}

In our study, pre-operative mean neck pain scores on the VAS were $6.53 \pm 1.15$ in Group A and $6.07 \pm 1.18$ in Group B ( $p=0.29)$, and pre-operative mean upper limb pain scores were $5.47 \pm 1.63$ and 5.8 $\pm 1.47(p=0.57)$, respectively. These pre-operative scores were not significantly different between the groups. The remaining overall mean neck pain scores on the VAS were $4.13 \pm 1.02$ in Group $A$ at 1 year, compared with $5 \pm 1.03$ in Group B. Regarding neck pain, compared to the pre-operative pain, both groups had significant improvement on the VAS $(p<0.05)$, and the improvements were significantly better in Group A $(p<0.05)$. The remaining overall average upper limb pain scores on the VAS were $3.07 \pm 1.48$ in Group A at 1 year, compared with $3 \pm 1.31$ in Group B $(p=0.89)$. With regard to the upper limb pain, compared to the preoperative pain, both groups had significant improvement on the VAS $(p<0.001)$, and there was no significant difference between the two groups ( $p>0.05)$.

Highsmith et al. documented in their study a comparison of pre-operative and post-operative neck pain VAS which showed a significant improvement in VAS scores in the fusion group $(p<0.01)$, and no improvement with slight worsening in the laminoplasty group, they explained the unimprovement in that laminoplasty group is that maintenance of some motion with laminoplasty may allow for this neck pain [10]. Blizzard et al. showed in their retrospective study a significant improvement in neck pain VAS in both groups with more significant improvement in the laminectomy and fusion group [15].

On the controversy, Manzano et al. in their prospective study showed a significant improvement of neck pain VAS in both groups, but the improvement was more significant in the laminoplasty group than in laminectomy and fusion group [11]. Most of the abovementioned studies match our results regarding the postoperative improvement of neck pain in both groups and that improvement is more significant in laminectomy and fixation favoring the concept that internal fixation minimizes movements which help to alleviate musculoskeletal pain. 


\section{NDI}

Regarding the NDI, both groups showed significant improvement at 1 year post-operative. However, there was no significant difference in postoperative improvement $(p=0.2)$ between the groups. Du et al. reported NDI scores at the final follow-up a significant improvement in the fusion group than the laminoplasty group [13]. Blizzard et al. results showed no significant difference between improvements in NDI between the two groups [15]. On the other hand, Manzano et al. confirmed that NDI improvement was significant in the laminoplasty group. However, there was no improvement in NDI in the laminectomy and fusion groups [11].

\section{Myelopathy scores}

In our series, there was an overall insignificant difference in the improvement between both groups regarding the Nurick's scores $(p=0.23$ ). Both groups showed a significant improvement at 1 year post-operative compared to the pre-operative values $(p<0.001)$. The results were similar using the mJOA. Yang et al. results showed significant improvement of outcome regarding Nurick's and MJOA scores with no significant difference in the improvement between laminectomy and fusion group and laminoplasty group [14]

Fehlings et al. results showed that there were significantly better improvements in mJOA scores in the laminoplasty compared to the laminectomy with fusion group ( $p=0.0069$ ) [16]. Manzano et al. results after 1 year showed that both laminoplasty and laminectomy and fusion showed improvements in Nurick grade, but only the laminoplasty group demonstrated a significant improvement in Nurick grade, while both laminoplasty and laminectomy with fusion improved equally in mJOA score [11]. Hence, both surgical modalities offer satisfactory treatment in DCM.

\section{Odom's criteria}

In our study, results showed no significant difference between the two groups after using Odom's criteria to evaluate the patient's satisfaction with the outcome of the procedure. In Group A, the outcome score using Odom's criteria was good or excellent in $80 \%$, while in Group B, the score was good or excellent in $73.3 \%$ ( $p>0.05)$. Highsmith et al. results showed that excellent and good outcomes were similar in both groups [10].

\section{Post-operative radiographic outcome (C2-7 Cobb's angle)}

In our study, there was no significant improvement in the C2-7 Cobb's angle compared to the pre-operative measures $(p>0.05)$. However, results showed that there was significantly better improvement in the Cobb's in the fusion group $(p<0.05)$. The significant increase in the post-operative Cobb's angle in our study could be explained by gentle neck remodeling in lordotic position before rod fixation. Woods et al. in their series showed that there was a significant decrease in Cobb's angle postoperatively compared to baseline angles and they explained these results by increased junctional kyphosis between fused segments and nonfused segments [17]. Lau et al. series showed that there was a post-operative improvement in the postoperative Cobb's angle in the laminectomy and fusion group which matches our results. Furthermore, their results showed a decrease in post-operative Cobb's angle in the laminoplasty group. However, there was no significant difference in post-operative cervical Cobb's angles between the two groups $(p=0.454)$ [12]

\section{Hospital stay}

In our study, the average hospital stay for significantly longer in the laminectomy and fusion group compared to the laminoplasty group $(p<0.05)$ which is similar to Lau et al. series [12]. However, Highsmith et al. series showed that the mean hospital stay was insignificantly longer in the laminoplasty group [10].

\section{Post-operative complication}

In our study, the rate of complications was nearly the same between both groups: In Group A, complications included two cases of dural tear (13.3\%), one case of C5 palsy $(6.7 \%)$, one case of transient weakness $(6.7 \%)$, and two cases of superficial infection (13.3\%). In Group B, complications included a case of instrumentation failure $(6.7 \%)$ and breakage of the hinged side of laminoplasty with neural compression by the plate and the patient presented with severe radiculopathy and mild upper limb weakness for which the patient required revision surgery and removal of the miniplates and completed as laminectomy and lateral mass fixation, a case of superficial infection $(6.7 \%)$, and a case of dural tear (6.7\%) Figure 1.

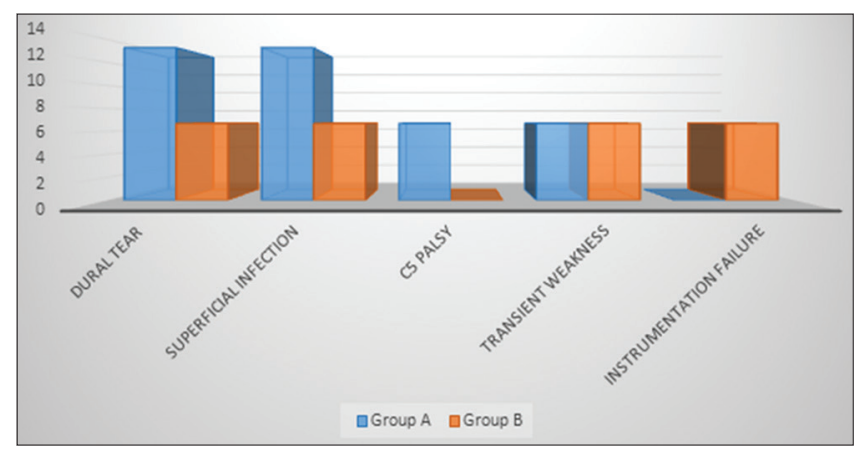

Figure 1: Comparison of complication rate among both groups

None of the two groups developed any of the following complications: Deep infection, worsening of myelopathy (all weaknesses reported in both groups were transient and improved in reassessment), vascular 
injury, or hematoma, and there were no mortality cases during the study period. Yang et al. results showed a postoperative single case of superficial wound infection in the laminectomy and fusion group (1.25\%) and no cases of wound infection in the laminoplasty group. Furthermore, results showed a single case of post-operative CSF leak in the laminoplasty group $(1.33 \%)$ and three cases in laminectomy and fusion group (4.55\%). The results of this retrospective study also showed a significant difference between post-operative C5 radiculopathy between laminectomy and fusion groups (11 cases, 16.67\%) compared with 3 cases (4\%) in the laminoplasty group, they explained this significant difference that preservation of the lamina prevents further backward shift of the spinal cord, thus minimizing traction on C5 roots [14].

Highsmith et al. results showed four cases of wound infection (13.3\%), two cases of hardware malposition (6.6\%), and one case of C5 palsy (3.3\%) in the laminoplasty group. Laminectomy and fusion groups showed also four cases of wound infection (15.3\%), two cases of hardware malposition $(7.6 \%)$, and one case of C5 palsy (3.8\%) with no significant difference regarding rate of complication between the two groups [10].

\section{Conclusion}

Both laminoplasty and laminectomy with fusion are excellent treatment options for patients with DCM and no procedure is superior to the other in management regarding the outcome of myelopathy. Laminoplasty was superior to laminectomy with fusion regarding blood loss, operative time, and hospital stay, which favors this option in elderly patients with a poor medical condition. On the contrary, laminectomy with fusion reduces neck pain significantly compared to the laminoplasty which pushes us to choose it if neck pain is the most eminent and agonizing presentation. This settles the concept that internal fixation minimizes movements which help to alleviate musculoskeletal pain. There was no significant difference in post-operative complications between these two procedures. Radiographically, laminectomy with fusion was superior in improving the cervical curvature.

\section{References}

1. Hu P, He Z, Cui J, Wan Y. Pathological changes of cervical spinal canal in cervical spondylotic myelopathy: A retrospective study on 39 cases. Clin Neurol Neurosurg. 2019;181:133-7. https://doi.org/10.1016/j.clineuro.2019.04.016 PMid:31039495

2. El-Ghandour NM, Soliman MA, Ezzat AA, Mohsen A, ZeinElabedin M. The safety and efficacy of anterior versus posterior decompression surgery in degenerative cervical myelopathy: A prospective randomized trial. J Neurosurg Spine. 2020;32(4):19. https://doi.org/10.3171/2020.2.spine191272

PMid:32357329

3. Kalsi-Ryan S, Singh A, Massicotte EM, Arnold PM, Brodke DS, Norvell DC, et al. Ancillary outcome measures for assessment of individuals with cervical spondylotic myelopathy. Spine (Phila Pa 1976). 2013;38(1):S111-22. https://doi.org/10.1097/ brs.0b013e3182a7f499

PMid:23963009

4. Bakhsheshian J, Mehta VA, Liu JC. Current diagnosis and management of cervical spondylotic myelopathy. Global Spine J. 2017;7(6):572-86. https://doi.org/10.1177/2192568217699208 PMid:28894688

5. Baron E, Young W. Cervical spondylotic myelopathy: A brief review of its pathophysiology, clinical course, and diagnosis. Neurosurgery. 2007;60(1):S35-41.

PMid:17204884

6. Sah S, Wang L, Dahal M, Acharya P, Dwivedi R. Surgical management of cervical spondylotic myelopathy. JNMA J Nepal Med Assoc. 2012;52(188):172-7. https://doi.org/10.31729/ jnma.374

PMid:23591248

7. Komotar RJ, Mocco J, Kaiser MG. Surgical management of cervical myelopathy: Indications and techniques for laminectomy and fusion. Spine J. 2006;6(6):252-67. https://doi.org/10.1016/j. spinee.2006.04.029

PMid: 17097545

8. Heary RF, MacDowall A, Agarwal N. Cervical spondylotic myelopathy: A two decade experience. J Spinal Cord Med. 2018;42(4):1-9. https://doi.org/10.1080/10790268.2018.147 1780

PMid:30048224

9. Yoon ST, Hashimoto RE, Raich A, Shaffrey $\mathrm{Cl}$, Rhee JM, Riew KD. Outcomes after laminoplasty compared with laminectomy and fusion in patients with cervical myelopathy: A systematic review. Spine (Phila Pa 1976). 2013;38(1):S183-94. https://doi.org/10.1097/brs.0b013e3182a7eb7c

PMid:23963000

10. Highsmith JM, Dhall SS, Haid RW, Rodts GE, Mummaneni PV. Treatment of cervical stenotic myelopathy: A cost and outcome comparison of laminoplasty versus laminectomy and lateral mass fusion. J Neurosurg Spine. 2011;14(5):619-25. https://doi. org/10.3171/2011.1.spine10206

PMid:21388285

11. Manzano GR, Casella G, Wang MY, Vanni S, Levi AD. A prospective, randomized trial comparing expansile cervical laminoplasty and cervical laminectomy and fusion for multilevel cervical myelopathy. Clin Neurosurg. 2012;70(2):264-76. https:// doi.org/10.1227/neu.0b013e3182305669

PMid:22251974

12. Lau D, Winkler EA, Than KD, Chou D, Mummaneni PV. Laminoplasty versus laminectomy with posterior spinal fusion for multilevel cervical spondylotic myelopathy: Influence of cervical alignment on outcomes. J Neurosurg Spine. 2017;27(5):508-17. https://doi.org/10.3171/2017.4.spine16831 PMid:28862572

13. Du W, Wang L, Shen Y, Zhang Y, Ding W, Ren L. Longterm impacts of different posterior operations on curvature, neurological recovery and axial symptoms for multilevel cervical degenerative myelopathy. Eur Spine J. 2013;22(7):1594-602. https://doi.org/10.1007/s00586-013-2741-5 PMid:23508336

14. Yang L, Gu Y, Shi J, Gao R, Liu Y, Li J, et al. Modified plate-only open-door laminoplasty versus laminectomy 
and fusion for the treatment of cervical stenotic myelopathy. Orthopedics. 2012;36(1):e79-87. https://doi. org/10.3928/01477447-20121217-23

15. Blizzard DJ, Caputo AM, Sheets CZ, Klement MR, Michael KW, Isaacs RE, et al. Laminoplasty versus laminectomy with fusion for the treatment of spondylotic cervical myelopathy: Shortterm follow-up. Eur Spine J. 2017;26(1):85-93. https://doi. org/10.1007/s00586-016-4746-3

PMid:27554354

16. Fehlings MG, Santaguida C, Tetreault L, Arnold P, Barbagallo G, Defino $\mathrm{H}$, et al. Laminectomy and fusion versus laminoplasty for the treatment of degenerative cervical myelopathy: Results from the AOSpine North America and international prospective multicenter studies. Spine J. 2017;17(1):102-8. https://doi. org/10.1016/j.spinee.2016.08.019

PMid:27597512

17. Woods BI, Hohl J, Lee J, Donaldson W, Kang J. Laminoplasty versus laminectomy and fusion for multilevel cervical spondylotic myelopathy. Clin Orthop Relat Res. 2011;469(3):688-95. https:// doi.org/10.1007/s11999-010-1653-5

PMid:21089002 